\title{
SUSTAINABLE CITIES AS ORGANISMS, A CIRCULAR THERMODYNAMICS PERSPECTIVE
}

\author{
M.-W. HO \\ Institute of Science in Society, UK.
}

\section{ABSTRACT}

More than $50 \%$ of us now live in cities while world population growth and urbanization continues unabated. There is an urgent need for policies that can address both the challenges and opportunities for sustainable development in urban settings.

Within the past two decades, the idea of cities as fractal structures resulting from social and economic processes led to a transition in thinking of cities as machines to cities as organisms. Independently, the concept of 'sustainable cities' had emerged earlier, with many successful implementations already underway.

I propose to define a sustainable city as one able to feed and power itself as much as possible using land and energy efficiently with the least environmental pollution and impact on climate change, minimizing wastes and recycling and reconverting wastes into resources.

Coherent fractal space-time structures are the key to a circular thermodynamics of organisms and sustainable systems that achieves the state of minimum entropy production and dissipation that Ilya Prigogine had proposed as a conjecture. In this article, I explain how the principles of circular thermodynamics can be applied to sustainable cities.

Keywords: Allometric scaling, cycles, energy capture and storage, fractal spacetime, minimum entropy production.

\section{INTRODUCTION}

Urbanization has been expanding rapidly within the past 200 years, emerging as the most pressing global problem of this century. Since the year 2006, those of us who live in cities have exceeded 50\% of the world population. Today, more than $80 \%$ of people in developed countries such as the United States are urbanised, and by 2050 , more than $75 \%$ of the world population will live in cities.

Geoffrey West at the Santa Fe Institute in the United States summed up the challenges of urbanization [1]: 'Cities are the origins of global warming, impact on the environment, health, pollution, disease, finance, economics, energy - they're all problems that are confronted by having cities.' On the other hand, he also noted that cities have proved to be the [2] 'engines of creativity', and places for wealth creation and economic growth. He called for $[1,3]$ a 'Grand Unified Theory of Sustainability.'In this article, I shall review current ideas on sustainable cities as fractals and organisms, and suggest how a circular thermodynamics of organisms and sustainable systems may be applied as guiding principles for making cities sustainable.

\section{SUSTAINABLE CITIES AND FRACTAL CITIES AS ORGANISMS}

It has long been recognised that cities can save energy on mass and food transport, and facilitate the provision of essential services for health, education, sanitation and energy, as well as building social communities [4]. The idea of sustainable cities goes back at least to the 1980s. For example, Richard Register coined the term ecocity in his book [5] Ecocity Berkeley: Building Cities for a Healthy Future. Architect Paul F. Downton founded the company Ecopolis in 1990 specializing in ecological architecture and bio-urban design [6] and published a book in 2009 [7].

There is no agreed definition for a sustainable city. I suggest the following as one that may be generally acceptable: a sustainable city should as far as possible be able to feed and power itself using land and energy efficiently with the least environmental pollution and impact on climate change, minimizing waste, and recycling and reconverting wastes into resources.

(C) 2015 WIT Press, www.witpress.com

ISSN: 1755-7437 (paper format), ISSN: 1755-7445 (online), http://www.witpress.com/journals DOI: 10.2495/DNE-V10-N2-127-139 
A long list of sustainable or ecocities are found in countries across the world [4], with indicators for sustainability typically in three areas - economy, environment and social - the details depending on local conditions [8]. Strong emphases are generally placed on green space, renewable energies and energy efficiencies, reduced carbon emissions, good transport, water availability and quality, air quality, and minimizing and recycling wastes for the environment; complete neighbourhood, equity and affordable housing, education, sanitation and health for the social; and employment rates especially in green jobs, and economic growth for the economy. Surprisingly, there is nothing on food and its availability, considering that 842 million people worldwide do not have enough to eat [9].

Stimulated by the science and mathematics of complex systems in the 1990s, substantial effort has been dedicated to understanding cities in terms of fractal geometry and dynamics [10]. Fractals are geometrical or mathematical objects with fractional dimensions instead of the usual integer 1, 2, 3 or 4 . They also have self-similar properties, i.e. they appear similar on different scales. Siena is a wonderful example of a fractal city (Fig. 1).

Fractals are also the key to living organization and characteristic of living organisms (as will be made clear later), and this led to the transition in thinking of cities as machines to cities as organisms [11]. While living cities have fractal properties that extend down to human scales, they are lacking or destroyed in modernist cities built to accommodate the automobile and population growth. These fractal properties are being recreated and recovered [12], e.g. in pedestrian walkways and precincts such as those along and across the River Thames in London [13]. A related move is 'smart growth' [14] in urban planning to avoid urban sprawl. It advocates compact, transit-oriented walkable, bicycle-friendly land use, with neighbourhood schools, complete streets that include safe access for bicycles, pedestrians, as well as for delivering foods, and mixed-use development that blends a combination of residential, commercial, cultural, institutional or industrial uses with a range of housing choices, all aimed at restoring connectivity and structures on human scales. Much attention is obviously being paid to the social aspects of sustainability.

Despite these promising developments, cities are still poorly understood. There is as yet no real science of cities [10], let alone a grand unified theory of sustainability [1,3]. Nevertheless, there are hints that a theory of sustainable cities may exist, and fractals very much part of it.

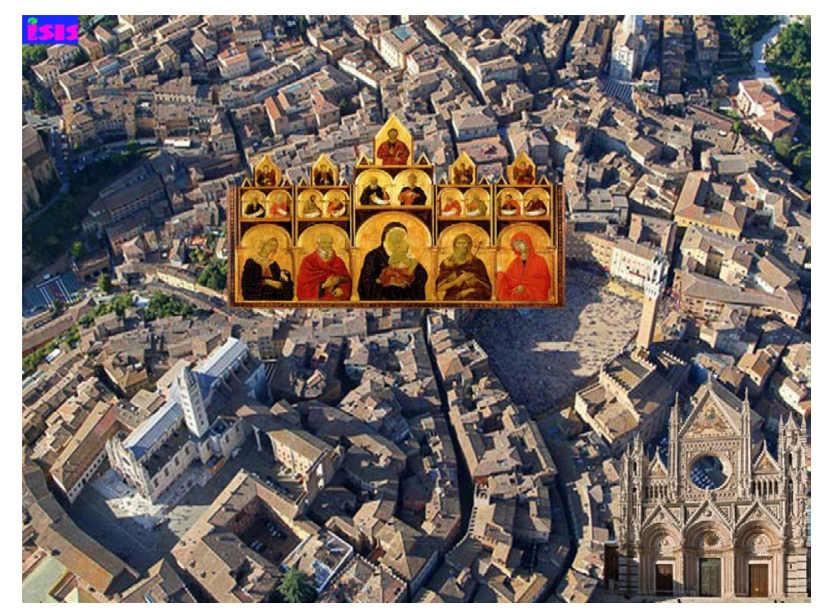

Figure 1: Fractal city of Siena with self-similar structures extending down to human scales of individual buildings (the façade of Siena Cathedral) and Duccio's polyptych of Madonna and Child and the Saints. 


\section{UNIVERSAL SCALING IN ORGANISMS AND CITIES BASED ON THERMODYNAMICS}

One of the most intriguing and best-known relationship in physiology is allometric scaling especially of resting metabolic rate with size,

$$
I=I_{0} M^{\beta}
$$

where $I$ is the resting metabolic rate, $M$ the body mass, and both $I_{0}$ and $\beta$ are constants. Plotting log $I$ against $\log \mathrm{M}$ gives a straight line with slope $\beta$ and intercept $\log I_{0}$. The value of $\beta$ is $3 / 4$, and it applies universally across the living world from giant redwood trees and whales all the way down to cells, mitochondria and the respiratory molecular complex, spanning 27 orders of magnitude [15]. This sublinear scaling $(\beta<1)$ means that there is economy of scale, larger organisms have proportionately lower resting metabolic rate, using energy more efficiently than smaller organisms. West and colleagues produced the first overarching theory [15-18] showing that allometric scaling depends on fractal networks optimised for transport, such as the circulatory system in mammals, trachea in insects, and xylem and phloem in plants. These fractal structures maximise the area across which they can take up and release resources and minimise the energy needed to deliver those resources throughout the organism. They are space-filling in three dimensions, but not quite three dimensional, and hence have a fractional dimension between 2 and 3 . They are similar over many scales, as characteristic of fractals, but unlike mathematical fractals that are self-similar over infinite scales, the real-life fractals terminate in finite units, as for example, actual metabolic units of the respiratory complexes.

The metabolic theory applies not just to the physiology of organisms, but also to ecology. As James Brown wrote in his MacArthur Award Lecture [19]: 'Metabolic theory predicts how metabolic rate, by setting the rates of resource uptake from the environment and resource allocation to survival, growth and reproduction, controls ecological processes at all levels of organization from individuals to the biosphere'. It is well known that metabolic rates increase exponentially with temperature, as described by the Boltzmann factor, $e^{-E / k T}$, where $E$ is the activation energy, $k$ is Boltzmann's constant and $T$ is the absolute temperature. This relationship holds over the range of normal temperature between $0^{\circ} \mathrm{C}$ and $40^{\circ} \mathrm{C}$. Combining the effects of body size and temperature gives

$$
I=i_{0} M^{3 / 4} e^{-E / k T}
$$

where $i_{0}$ is a normalization constant independent of body size and temperature. Equation (2) predicts that the natural logarithm of the mass-corrected whole organism metabolic rate should be a linear function of the inverse absolute temperature $(1 / k T)$, the slope of which yields the activation energy of metabolism. The prediction proved to be true for birds and mammals, fish, amphibians, reptiles, invertebrates, unicellular organisms and plants. The slope (activation energy) was the same over all the groups at $0.69 \mathrm{eV}$. This activation energy is within the range $(0.60-0.70 \mathrm{eV})$ commonly reported for aerobic respiration.

Most intriguingly, West and others also observed allometric scaling in cities; raising the possibility that cities too, may be considered as organisms [20]. For example, cities appear to scale sublinearly with size as measured by population for infrastructure such as number of petrol stations, length of roads, electric lines, etc., with economy of scale of about 15\% (scaling constant of 0.85). A similar sublinear scaling has been claimed for carbon footprints suggesting that larger cities are greener than small ones. More surprisingly, cities also scale superlinearly with by approximately the same amount or size $(\beta \sim 1.15)$ in gross domestic product, wages, income, creativity (number of patents), etc. However, a new analysis using state-of-the-art clustering technique for identifying 
cities and the most detailed available data shows that large cities are much less green than small ones. Carbon emissions scale superlinearly, with $\beta=1.46 \pm 0.02$. Income level, on the other hand, scales superlinearly only for those with per capita income higher than $\$ 37,235$, whereas for those with incomes lower than that, the scaling is sublinear; in other words, the low-paid get less as the size of the city size increases $[21,22]$.

West and Brown [15] are right in linking the universality of allometric scaling in physiology to thermodynamics, which in general terms is the transformation of energy and materials in metabolism that enables organisms to develop and grow (accumulate biomass); and the universality of the mass-corrected scaling relationship is truly impressive [19]. But without a clear thermodynamic theory, they appealed to Darwinian natural selection for optimization.

My own conjecture is that it can be explained in terms of a circular thermodynamics of organisms and sustainable systems that results in dissipationless (zero entropy) energy transfer and transformation in the ideal; and that is also implied in the quantum coherence of organisms. The detailed empirical evidence and theoretical arguments for circular thermodynamics and quantum coherence of organisms are presented in The Rainbow and the Worm, the Physics of Organisms [23] (see also [24-26]). In [24] Living Rainbow $\mathrm{H}_{2} \mathrm{O}$, I elaborate on the universal metabolism in living organisms based on splitting and recombining water in photosynthesis and respiration that underlies the thermodynamics of universal allometric scaling.

To think of cities as organisms [2,3], we must concentrate on the thermodynamics - the transformation of energy and resources - which is nothing but the economy of cities; and it could be a good guide to making cities (and their economies) sustainable.

\subsection{First principles}

\section{CIRCULAR THERMODYNAMICS OF SUSTAINABLE CITIES}

The first thing to note is that organisms do not make their living by heat transfer. They are not heat engines. Instead, they are isothermal systems far from thermodynamic equilibrium dependent on the direct transfer of molecular energy by proteins and other macromolecules acting as 'quantum molecular energy machines'.

For isothermal processes, the change in Gibbs free energy $\Delta G$ (thermodynamic potential for doing work at constant temperature and pressure) is

$$
\Delta G=\Delta H-T \Delta S
$$

where $\Delta H$ is the change in enthalpy (heat content), $T$ is temperature in deg $\mathrm{K}$, and $\Delta S$ is the change in entropy, the measure of dissipation of energy.

Thermodynamic efficiency requires that $\Delta S$ approaches 0 (least dissipation) and $\Delta H=0$, or $\Delta G=0$ via entropy-enthalpy compensation, i.e. entropy and enthalpy changes cancelling each other out. We shall see how organisms manage to do that.

\subsection{Importance of energy capture and storage}

For a system to keep far away from thermodynamic equilibrium - death by another name - it must capture energy and materials from the environment to develop, grow and recreate itself from moment to moment during its life-time, and also to reproduce and provide for future generations, which is all part and parcel of sustainability. The key to understanding the thermodynamics of the living system is not so much energy flow as energy capture and storage under energy flow to create a reproducing life cycle (Fig. 2). 


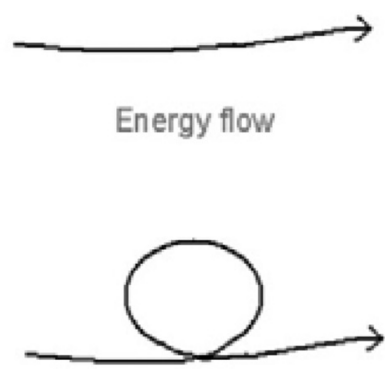

Energy storage

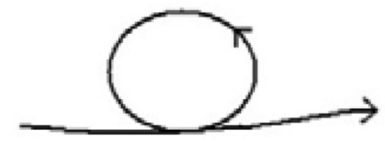

Reproducing life cycle coupled to energy flow

Figure 2: Energy capture and storage for a reproducing life cycle.

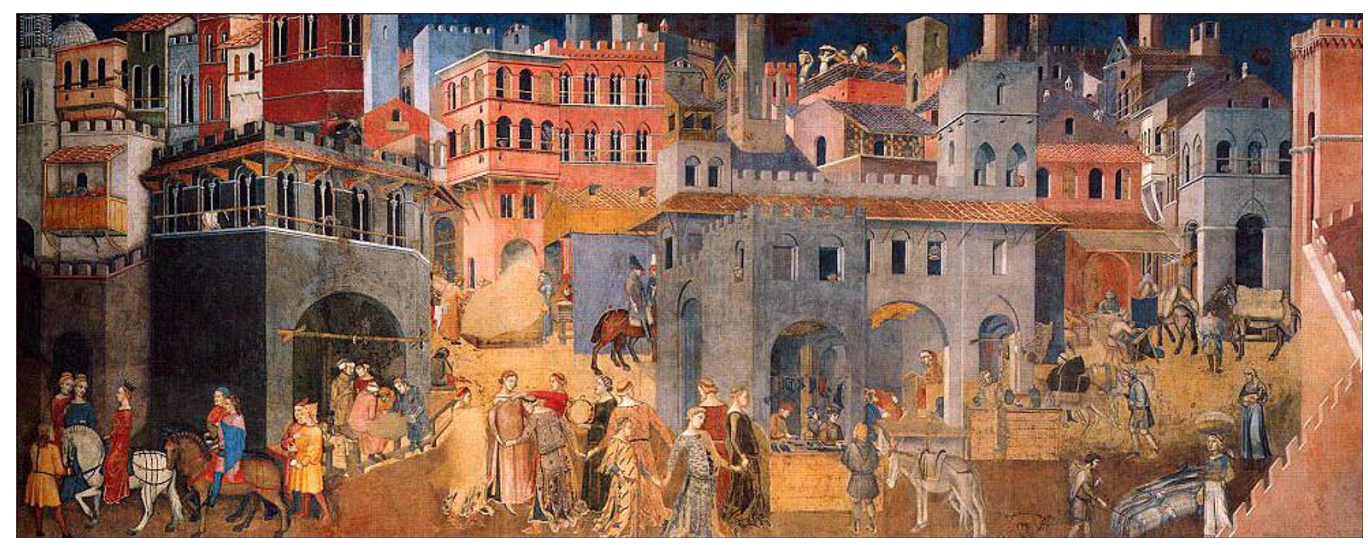

Figure 3: Lorenzetti's idealised Siena city state representing peace and prosperity.

The analogy with a city is clear; the city too, is far from thermodynamic equilibrium, it captures and stores resources to build physical structures that keep resources circulating within and keep the city alive. Figure 3 is a remarkable fresco of the idealised 14th century autonomous Siena city state by Lorenzetti, representing peace and prosperity of a well-governed city [27]. The thin city wall is emblematic of the fragile physical closure against invaders. Physical closure is perhaps much less important for the survival and autonomy of the city than dynamic closure due to the characteristic space-times of processes that create the fractal dynamics. 


\subsection{Characteristic spacetimes and fractal dynamics}

Characteristic spacetime is a very important concept all too often ignored. All real processes and objects have characteristic spacetimes. In the organism, the heart $\left(10^{-1} \mathrm{~m}\right)$ beats in a second, nerve cells $\left(10^{-5} \mathrm{~m}\right)$ fire in $10^{-1} \mathrm{~s}$ or faster, and protons $\left(10^{-15} \mathrm{~m}\right)$ and electrons $\left(10^{-17} \mathrm{~m}\right)$ move in $10^{-12}$ $10^{-15} \mathrm{~s}$. Cells divide in minutes, and physiological states change cyclically in hours, a day, a month or a year.

Living activities are organised by their characteristic spacetimes in a coherent fractal hierarchy. Processes with matching spacetimes interact most strongly with one another through resonance, but also link up to the entire hierarchy.

Similarly, cities have fractal hierarchies of activities in buying and selling, manufacturing and scavenging, imports and exports, borrowing and lending, etc., construction and deconstruction, which must also match and link up.

\subsection{Cycles are the key to coherent fractal spacetimes}

Cycles are the key to the fractal spacetime organisation of living systems. The way to match spacetimes and link up the entire hierarchy is through cycles. Practically all living activities come in cycles, i.e. biological rhythms. Cycles are also ubiquitous in the physical universe. And some cosmologists even believe the universe itself is cyclic [28]. The possibility of cycles in the living world coupling and linking up to those in the physical universe is surely why life exists, and indeed some would argue, indicates that the entire universe may be alive.

The coupled cycles form a nested fractal self-similar structure: the life cycle is made up of small cycles, each small cycle has similar smaller cycles within, spanning characteristic spacetimes from sub-nanometre to metres and from $10^{-15} \mathrm{~s}$ to hours and years (Fig. 4).

Cycles enable activities to be coupled together, so energy yielding processes can transfer energy directly to those requiring energy. And the direction can be reversed when necessary. Cooperativity and reciprocity is the hallmark of a sustainable system. This is an extended Onsager reciprocity relation in thermodynamics that strictly applies only to the steady state (see [23]). What it means in

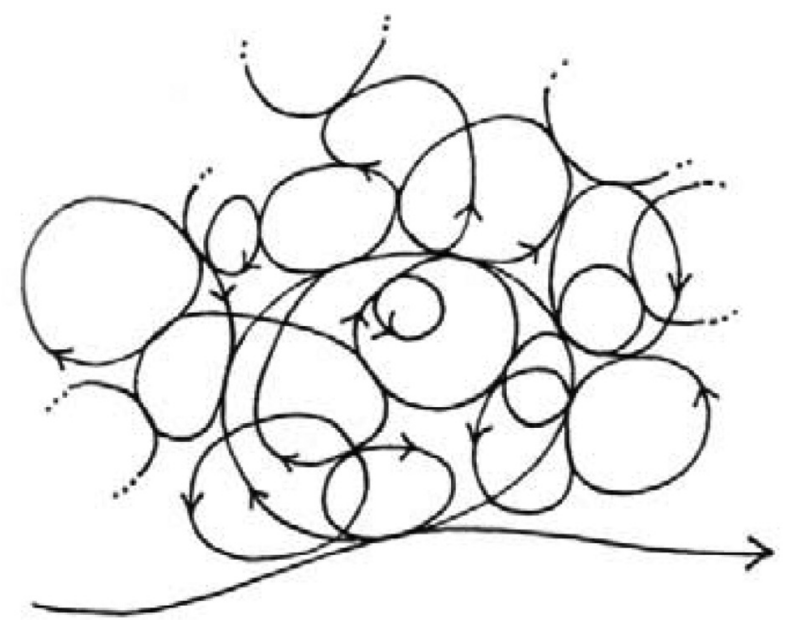

Figure 4: The fractal structure of coupled activity cycles in living organisms. 
practice is that energy can be concentrated to any local point where it is needed, and conversely spread globally from any local point. In that way, the fractal hierarchy of coupled cycles maximises both local autonomy and global cohesion.

To get an idea of such coupled cycles, one needs to look no further than charts of biochemical metabolic pathways [29]; most if not all of the reactions go both ways, depending on the local concentrations of reactants and products. Biochemical recycling is ubiquitous; there are numerous scavenging or salvaging pathways for the recovery of building blocks of proteins, nucleic acids, glycolipids, and even entire proteins.

The fractal hierarchy of cycles confers dynamic stability as well as autonomy to the system on every scale. Thermodynamically, no net entropy is generated in the case of perfect cycles; hence the system can maintain its organisation.

The fractal structure effectively partitions the organism into a hierarchy of systems within systems defined by the extent of equilibration of energies. Thus, energy equilibrated (evenly spread out) within a smaller spacetime will still be out of equilibrium in the larger system encompassing the first, and hence capable of doing work $[23,26]$.

Consequently, there are two ways to mobilise energy efficiently with entropy change approaching zero, very slowly with respect to the characteristic time so it is reversible at every point, or very rapidly with respect to the characteristic time, so that in both cases the energy remains stored (in a coherent non-degraded form) as it is mobilised. It is that which enables the organism to simultaneously achieve the most efficient (almost dissipationless) equilibrium and far-from-equilibrium energy transfer.

The nested dynamical structure also optimises the kinetics of energy mobilisation. For example, biochemical reactions depend strictly on local concentrations of reactants, which are extremely high, as their extent of equilibration is typically at nanometre dimensions (in nanospaces).

\subsection{Spacetime differentiation directly proportion to energy storage and resource residence time}

The degree of fractal spacetime differentiation in the living system is directly proportional to its energy storage capacity and material residence time. In individual organisms, these translate to vitality and health; in ecosystem/sustainable systems, these translate to biodiversity (species richness) and biomass (productivity). There is now abundant evidence that biodiversity and productivity go together in agricultural systems (see [30]). Biodiverse agricultural systems based on the circular economy of nature are many times more productive than industrial monocultures in which all fractal spacetime differentiation has been destroyed. Monocultures need chemical fertilizers on account of barren soils that cannot retain or recycle nutrients, and pesticides for want of pollinators and other beneficial animals and plants that could control pests.

For a city, the fractal structure maximises the retention of resources (and wealth) within the city, where they circulate in a hierarchical way, benefiting local economies at every level, encouraging diversity and diversification, which in turn feedback to benefit local economies.

Re-use and recycling make perfect sense in prolonging the retention of useful resources in the system. So does cooperation and reciprocity in the coupled cycles of giving and taking among local businesses and people in general, in place of the dominant misguided culture of relentless competition.

\subsection{Fractals mathematically isomorphic to quantum coherence}

The fractal structure maximises both global connectivity and local autonomy, which is the hallmark of quantum coherence [23]. Coincidentally, there is now a formal connection established between 
fractals and quantum coherence. Giuseppe Vitiello at Salerno University, Italy, has proven that fractals are mathematically isomorphic with squeezed quantum coherent states (in which Heisenberg's uncertainty relation is minimum) [31]. The full implications of this extremely important result are yet to be worked out. But it gives additional support to the equivalence between the zero-entropy ideal of circular thermodynamics and quantum coherence.

\subsection{Zero-entropy ideal and minimum entropy production}

In the ideal - approached most closely by the healthy mature organism and the healthy mature ecosystem - an overall internal conservation of energy and compensation of entropy $(\Sigma \Delta S=0)$ is achieved. In this state of balance, the system organization is maintained and dissipation minimum; i.e. the entropy exported to the environment also approaches zero, $\Sigma \Delta S \geq 0$ (Fig. 5).

Internal entropy compensation (and energy conservation) implies that there is free variation in microscopic states within the macroscopic system; i.e. the internal microscopic detailed balance of classical steady state theory is violated.

For an organism, it means that detailed energy balance is not necessary at every point within the system. Most often, parts of it are in deficit, and severely so when one needs to run away from a tiger knowing that the energy can be replenished after a successful escape. The same applies to ecosystems: all species are in a sense storing energy and resources (nutrients) for every other species via complex food webs and other symbiotic relationships. That is why biodiverse ecosystems and agricultural systems are more resistant and resilient to stress and environmental extremes.

For a sustainable city, all wealth and other resources are shared, either directly or indirectly. A proper city bank will see to it that excess wealth generated somewhere in the city can be directed in timely fashion to help those in need, or to finance key innovations and diversifications.

The above considerations give rise to the prediction that a sustainable system maximises cyclic, non-dissipative flows while minimizing dissipative flows, i.e. it tends towards minimum entropy production as conjectured by Ilya Prigogine [32] (This also accords with the asymptotic stability of the quantum coherent state [23], in which entropy is effectively zero).

In other words, minimum entropy production requires abandoning the principle of microscopic detailed balance of the classical steady state, which applies at near-to-equilibrium condition. This is most crucial for sustainability.

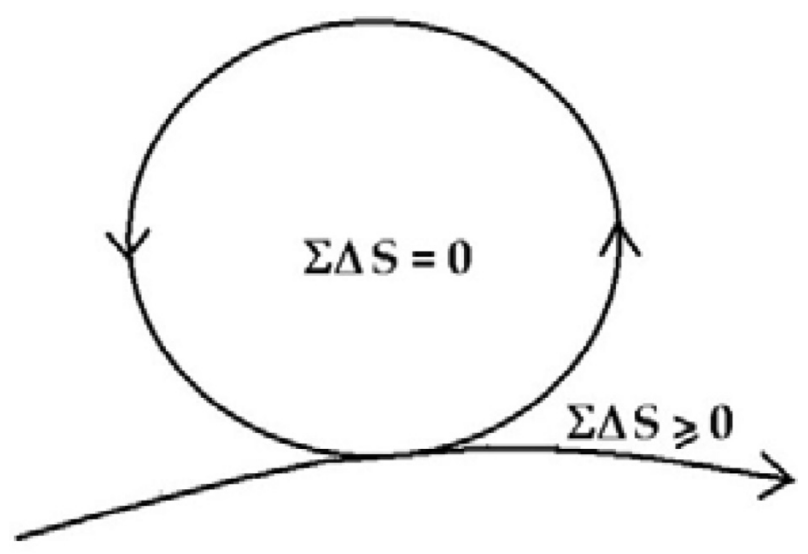

Figure 5: The zero-entropy ideal of circular thermodynamics. 


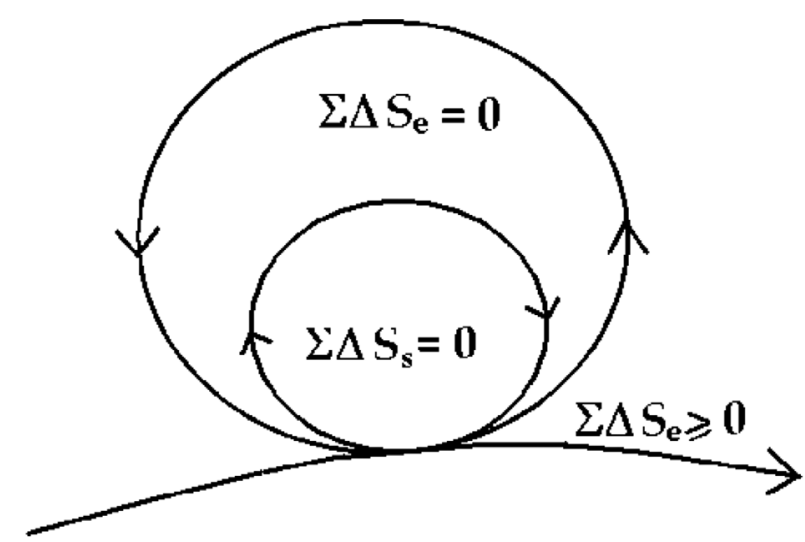

Figure 6: The coupled flows of system and ecological cycles in a sustainable system.

\subsection{A sustainable system needs to sustain the ecosystem on which it depends for input}

Minimum entropy production means that little or no entropy is exported to the environment. As the system depends on environmental input, entropy and wastes exported to the environment will simply mean diminished environmental input. Yet, generations of economists persist in speaking of economic growth as though the environment does not exist. Figure 6 makes it explicit that an organism or a sustainable system is coupled to its ecological environment, such that smaller ecosystems are embedded and coupled to larger and larger ones, ending with the entire Earth ecosystem.

For a city with ready access to air travel in a globalised world, the implications are profound. Not only its immediate ecological environment needs to be conserved, a sustainable city must take care not to over-exploit ecosystems in other countries especially in the developing world, because ultimately, the entire global fractal ecosystem is one. This also shows why exploitation and unequal exchanges in general are bad for sustainability.

Over-exploitation of people leads to over-exploitation of the environment both because it drives the exploited to faster deplete and degrade Earth's resources, and/or creates false 'wealth' for the exploiter to over-consume. Equity and self-sufficiency make perfect sense in this context. Cities can and should produce as much of its own food as possible in urban and per-urban green spaces and revive its local markets, which are great for rebuilding and revitalising local communities.

\section{SOME APPLICATIONS}

\subsection{Circular economy in business}

Circular economy if not circular thermodynamics has been enthusiastically championed by Dame Ellen MacArthur since 2010 [33]. The Ellen MacArthur Foundation has produced reports with analyses from McKinsey highlighting an annual trillion dollar opportunity globally in net material cost-savings for companies making the transition to circular economy. And big companies and governments all over Europe have indeed signed up to the 'Circular Economy 100' that the Foundation has launched, pledging design for longevity, service, re-use in manufacture, and material recovery and minimizing wastes. 
5.2 The dyke-pond system and dream farm 2

I began thinking about cycles and circular thermodynamics in the first edition of Rainbow Worm [23] published in 1993, and started to use the term 'circular economy' for the dyke-pond system of Pearl River Delta in China, which I visited in 2006 [34] and discovered that 'circular economy' is already in mainstream and official discourse in China, albeit also restricted to the manufacturing and service industries sectors [35].

Leaving out agriculture - the primary production of the economy - does not make sense, especially for the 'green economy' on everyone's lips, and certainly runs counter to circular thermodynamics. Industrial monoculture is completely non-circular, it is also decidedly not green as it pollutes the environment, requires massive inputs in energy and is responsible for huge amounts of carbon emissions (see [30]). It is now generally recognised that a paradigm change from industrial to agro-ecological farming is urgently needed to feed the world that at the same time can best mitigate and adapt to climate change [36].

The dyke-pond system evolved over two thousand years, perfected by generations of Chinese farmers into a paradigmatic circular economy of intensive agriculture. It depends on maximising internal inputs between land and water, optimising the efficient use of resources while minimising wastes, and transforming wastes into resources. One version is shown in Fig. 7.

Numerous cycles (I counted 15 in all) are obviously involved in keeping resources within the system to minimise dissipation and prevent pollution of the general environment. Dyke-pond systems are so productive that they supported an average of 17 persons per hectare in their heyday, compared with the 'carrying capacity' of about 2 persons per ha stipulated by United Nations Food and Agriculture Organization [38].

I extended the dyke-pond system by incorporating renewable energies including biogas from anaerobic digestion of wastes into a Dream Farm 2. One version is presented in Fig. 8 (slightly modified from $[30,38,39])$. If Dream Farm 2 is generally adopted, for a country like China, it is estimated that more than $40 \%$ of energy consumption could be saved by anaerobic digestion alone [38]. With the addition of renewable energies such as solar, wind, or micro-hydroelectric, such farms could provide more energy than they can use, leaving excess for export to the city nearby, while also compensating substantially for carbon emissions. As a peri-urban farm, it helps provide food security and healthy nutrition for the city dwellers (a key indicator of sustainability), and at greatly

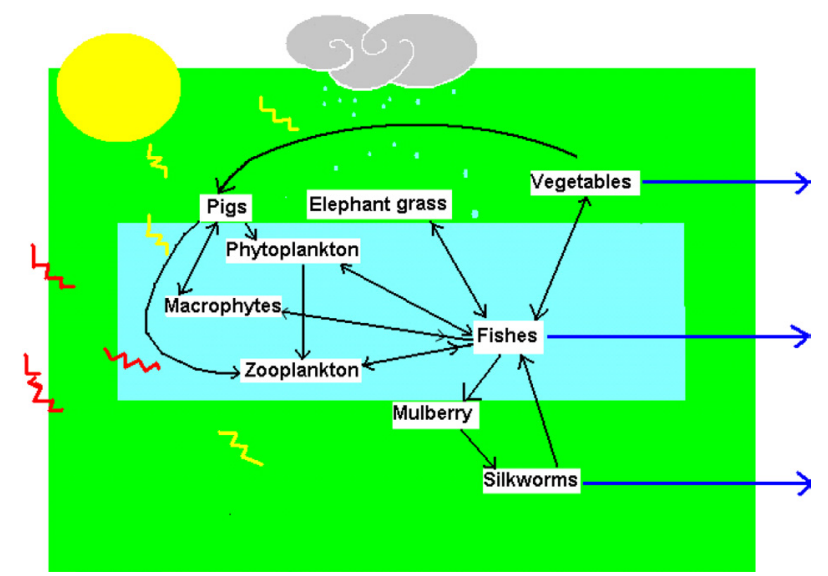

Figure 7: The circular economy of a dyke-pond system in China's Pearl River Delta. 


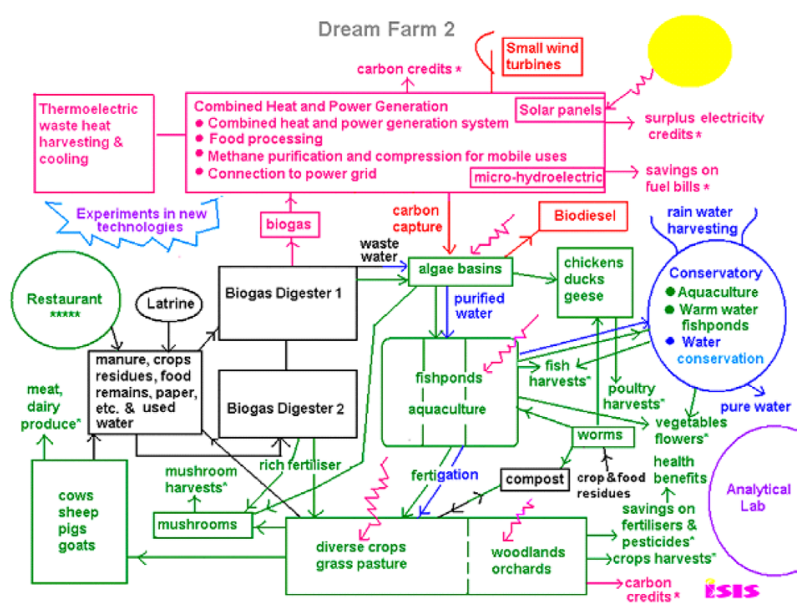

Figure 8: A food and energy self-sufficient farm run on the circular economy of nature.

reduced carbon footprint. In addition, it frees up land in rural areas to support wild life to protect and increase natural biodiversity.

\section{CONCLUSIONS}

To conclude, the principles of circular thermodynamics can help cities become as sustainable as organisms. A sustainable city has a dynamic fractal hierarchy of activities that bridges all spacetimes. The coherent fractal hierarchy maximises cyclic activities that enables the most efficient transformation and exchanges of resources, goods and services over all spacetimes on a symbiotic and reciprocal basis. It maximises both global cohesion and local autonomy, such that energy and resources could be readily shared from local to global and vice versa. It minimises wastes and recycles wastes into resources thereby achieving the state of minimum dissipation that protects its own organization, as well as safeguarding the ecological environment on which it depends for input. These circular thermodynamic principles are not difficult to implement, and are already widely implemented in sustainable cities all over the world. Now is the time to move ahead to meet both the challenges and opportunities in making cities sustainable.

\section{ACKNOWLEDGMENTS}

I am very grateful to Carlos Brebbia and the Committee of the Wessex Institute for awarding me the 2014 Prigogine Medal, and to the University of Siena for hosting the conference on Sustainable Cities, which provided the major impetus for my venturing into this topic. Many thanks also to my son Adrian Ho and my husband Peter Saunders for their help in preparing this report. Robert Ulanowicz has provided many astute comments and suggestions for improving the manuscript.

\section{REFERENCES}

[1] West, G., The surprising math of cities and corporations. TEDGlobal 2011, available at https:// www.ted.com/talks/geoffrey_west_the_surprising_math_of_cities_and_corporations, July 2011.

[2] Bettencourt, L. \& West, G., A unified theory of urban living. Nature, 447, pp. 912-913, 2010. doi: http://dx.doi.org/10.1038/467912a 
[3] West, G., Life from cells to cities: are they sustainable? Boston University Lecture, available at https://www.youtube.com/watch?v=etfRE5-YlXs, 8 May 2013.

[4] Wikipedia, Sustainable city, available at http://en.wikipedia.org/wiki/Sustainable_city, 4 July 2014.

[5] Register, R., Ecocity Berkeley: Building Cities for a Healthy Future, North Atlantic Books: Berkeley, 1987.

[6] Downton, P.F., Wikipedia, available at http://en.wikipedia.org/wiki/Paul_F_Downton, 31 May 2014.

[7] Downton, P.F., Ecopolis: Architecture and Cities for a Changing Climate, Springer: Berlin, and CSIRO, Australia, 2009. doi: http://dx.doi.org/10.1007/s10980-009-9366-4

[8] Indicators for Sustainability, How Cities Are Monitoring and Evaluating Their Success, Sustainable Cities International: Vancouver, November 2012.

[9] 10 Hunger Facts for 2014, World Food Programme, available at https://www.wfp.org/ stories/10-hunger-facts-2014, 30 December 2013.

[10] Batty, M. \& Longley, P., Fractal Cities: A Geometry of Form and Function, Academic Press: London, 1994.

[11] Batty, M., Building a Science of Cities, available at http://www.complexcity.info/, 30 October 2011. doi: http://dx.doi.org/10.1016/j.cities.2011.11.008

[12] Salingaros, N.A., Connecting the fractal city. Keynote speech. 5th Biennial of towns and town planner in Europe (Barcelona, April 2003). Published in Planum The European Journal of Planning On-line (March 2004). Reprinted as Chapter 6 of Principles of Urban Structure, Techne Press: Amsterdam, Holland, 2005.

[13] Thames path. National Trails, http://www.nationaltrail.co.uk/thames-path (accessed 4 February 2015).

[14] Smart Growth, Wikipedia, available at http://en.wikipedia.org/wiki/Smart_growth, 10 July 2014.

[15] West, G.B. \& Brown, J.H., The origin of allometric scaling laws in biology from genomes to ecosystems: towards a quantitative unifying theory of biological structure and organization. $J$ Exp Biol, 208, pp. 1575-1592, 2005. doi: http://dx.doi.org/10.1242/jeb.01589

[16] West, G.B., Brown, J.H. \& Enquist, B.J., A general model for the origin of allometric scaling laws in biology. Science, 276, pp. 122-126, 1997. doi: http://dx.doi.org/10.1126/science.276.5309.122

[17] Enquist, B.J., West, B.G., Charnov, E.L. \& Brown, J.H., Allometric scaling of production and life-history variation in vascular plants. Nature, 401, pp. 907-911, 1999. doi: http://dx.doi. org/10.1038/44819

[18] Gilloly, J.F., Brown, J.H., West, G.B., Savage, V.M. \& Charnov, E.L., Effects of size and temperature on metabolic rate. Science, 293, pp. 2248-2251, 2001. doi: http://dx.doi.org/10.1126/ science. 1061967

[19] Brown, J.H., Toward a metabolic theory of ecology. Ecology, 85, pp. 1771-1789, 2004. doi: http://dx.doi.org/10.1890/03-9000

[20] Ho, M.W., "Grand Unified Theory of Sustainability" for cities? Science in Society, 64, pp. 32-36, 2014.

[21] Oliveria, E.A., Andrade, Jr., J.S. \& Makse, H.A., Large Cities are Less Green, available at arXiv:1401.7720v2 and http://arxiv.org/abs/1401.7720, 18 June 2014. doi: http://dx.doi. org/10.1038/srep04235

[22] Ho, M.W., Larger cities in USA less green than small ones. Science in Society, 64, pp. 26-27, 2014. 
[23] Ho, M.W., The Rainbow and the Worm, the Physics of Organisms, 3rd edn., World Scientific, 2008. doi: http://dx.doi.org/10.1142/6928

[24] Ho, M.W., Living Rainbow H2O, World Scientific and Imperial College Press, 2012. doi: http://dx.doi.org/10.1142/9789814390903

[25] Ho, M.W. \& Ulanowicz, R.E., Sustainable systems as organisms? BioSystems, 82, pp. 39-51, 2005. doi: http://dx.doi.org/10.1016/j.biosystems.2005.05.009

[26] Ho, M.W., Circular economy of organisms and sustainable systems. Systems, 1, pp. 30-49, 2013. doi: http://dx.doi.org/10.3390/systems 1030030

[27] Harskamp, J. \& Dijstelberge, P., Piazza del Campo (Siena) or rather: not the Piazza del Campo..Streets \& Books - An Intertwined Cultural History, available at http://abeautifulbook. wordpress.com/2013/11/17/, 17 November 2013.

[28] Ho, M.W., Golden cycles of organic spacetimes. Science in Society, 62, pp. 32-35, 2014. doi: http://dx.doi.org/10.1016/j.enpol.2013.09.060

[29] Metabolic Pathways. Sigma Aldrich, http://www.sigmaaldrich.com/content/dam/sigma-aldrich/ docs/Sigma/General_Information/metabolic_pathways_poster.pdf (accessed 27 October 2014).

[30] Ho, M.W., Burcher, S., Lim, L.C. et al. Food Futures Now $(*$ Organic *Sustainable *Fossil Fuel Free), ISIS/TWN: London and Penang, available at http://www.i-sis.org.uk/foodFutures. php, 2008.

[31] Vitiello, G., On the isomorphism between dissipative systems, fractal self-similarity and electrodynamics. Toward an integrated vision of nature. Systems, 2, pp. 203-216, 2014. doi: http:// dx.doi.org/10.3390/systems2020203

[32] Prigogine, I., Time, Structure and Fluctuations. Nobel Lecture, http://www.nobelprize.org/nobel_prizes/chemistry/laureates/1977/prigogine-lecture.pdf, 8 December 1977.

[33] Ellen MacArthur Foundation, http://www.ellenmacarthurfoundation.org/ (accessed 26 October 2014).

[34] Ho, M.W., Circular economy of the dyke-pond system. Science in Society, 32, pp. 38-41, 2006.

[35] Ho, M.W., Sustainable agriculture, green energies \& the circular economy. Science in Society, 46, pp. 8-13, 2010.

[36] Ho, M.W., Paradigm shift urgently needed in agriculture, UN agencies call for an end to industrial agriculture and food system. Science in Society, 60, pp. 4-19, 2013.

[37] FAO, Agriculture Towards the Year 2010, Food and Agriculture Organization of the United Nations: Rome, Italy, 1995.

[38] Ho, M.W., Sustainable agriculture and off-grid renewable energy (Chapter 1, Commentary XIII). Wake up before it is Too Late, Make Agriculture Truly Sustainable Now for Food Security in a Changing Climate, Trade and Environment Review 2013, UNCTAD: Geneva, pp. 19-21, 2013.

[39] Ho, M.W., Sustainable agriculture essential for green circular economy. ISIS Lecture in Ten+One Conference, Bradford University, http://www.i-sis.org.uk/sustainableAgriculture EssentialGreenCircularEconomy.php (29 November-1 December 2010). 